\title{
MicroRNA-335 and its target Rock1 synergistically influence tumor progression and prognosis in osteosarcoma
}

\author{
YONG WANG $^{1 *}$, NINGNING WANG ${ }^{2 *}$, XIANDONG ZENG ${ }^{3}$, JIE SUN $^{4}$, \\ GUANGBIN WANG ${ }^{5}$, HUIMIAN XU ${ }^{6}$ and WEI ZHAO ${ }^{1}$ \\ Departments of ${ }^{1}$ Orthopedics, ${ }^{2}$ Cardiology, ${ }^{3}$ Surgical Oncology and ${ }^{4}$ Pathology, \\ Central Hospital Affiliated to Shenyang Medical College, Shenyang, Liaoning 110024; \\ ${ }^{5}$ Department of Orthopedics, Shengjing Hospital of China Medical University, Shenyang, Liaoning 110072; \\ ${ }^{6}$ Department of Surgical Oncology, The First Hospital of China Medical University, Shenyang, Liaoning 110001, P.R. China
}

Received July 24, 2015; Accepted January 4, 2017

DOI: $10.3892 / \mathrm{ol} .2017 .5818$

\begin{abstract}
MicroRNA (miR)-335 and Rho-associated serine-threonine protein kinase 1 (Rock1) is ectopically expressed in multiple malignant tumors including osteosarcoma. The present study aimed to clarify whether the combined ectopically expressed miR-335 and Rock1 was correlated with clinicopathological features and prognosis in patients with osteosarcoma. The expression of miR-335 and Rock1 in 91 osteosarcoma tissue samples and 47 noncancerous bone tissues were determined respectively by in situ hybridization and immunohistochemistry. The association between miR-335 and Rock1 expression with the clinicopathological features of osteosarcoma was calculated using the Pearson's $\chi^{2}$ test. Spearman's correlation analysis was used to study the association between the miR-335 and Rock1 expression. Survival curves were drawn using the Kaplan-Meier method. Univariate and multivariate analysis was performed using the Cox's proportional hazard regression model to allow the prognostic values to be assessed. Expression levels of miR-335 were significantly reduced in osteosarcoma tissues $(\mathrm{P}<0.001)$, compared with that in noncancerous bone tissues, while Rock1 expression was significantly increased in osteosarcoma tissues $(\mathrm{P}<0.001)$. A strong correlation between miR-335 and Rock1 expression was also shown $(\mathrm{P}<0.001)$. Decreased miR-335
\end{abstract}

Correspondence to: Dr Wei Zhao, Department of Orthopedics, Central Hospital Affiliated to Shenyang Medical College, 5 South Seven West Road, Tiexi, Shenyang, Liaoning 110024, P.R. China

E-mail: zhaowei332@126.com

Dr Xiandong Zeng, Department of Surgical Oncology, Central Hospital Affiliated to Shenyang Medical College, 5 South Seven West Road, Tiexi, Shenyang, Liaoning 110024, P.R. China

E-mail: ZXD_landy1116@163.com

*Contributed equally

Key words: microRNA-335, Rock1, combined expression, osteosarcoma, survival expression was identified to be positively associated with higher clinical stage $(\mathrm{P}=0.004)$ and distant metastasis $(\mathrm{P}=0.016)$, while elevated expression levels of Rock1 was positively associated with a larger tumor size $(\mathrm{P}=0.013)$, higher clinical stage $(\mathrm{P}=0.027)$ and distant metastasis $(\mathrm{P}=0.022)$. The combined high expression of Rock1 and low expression of miR-335 was clearly associated with distant metastasis $(\mathrm{P}=0.010)$ and a higher clinical stage $(\mathrm{P}=0.010)$. Patients with elevated Rock1 or decreased miR-335 expression exhibited a worse overall survival (OS) and disease-free survival (DFS) compared with patients with decreased Rock1 or increased miR-335 $(\mathrm{P}<0.001$ for the two). In addition, patients with decreased miR-335 and increased Rock1 had the worst OS and DFS $(\mathrm{P}<0.001$ for the two). In multivariate survival analysis, clinical stage $(\mathrm{P}=0.002$ for DFS, $\mathrm{P}=0.015$ for $\mathrm{OS})$, distant metastasis $(\mathrm{P}=0.024$ for DFS, $\mathrm{P}=0.002$ for $\mathrm{OS})$, low expression of miR-335 $(\mathrm{P}<0.001$ for DFS, $\mathrm{P}=0.002$ for OS) and combined depressed miR-335 and elevated Rock1 $(\mathrm{P}=0.021$ for $\mathrm{DFS}, \mathrm{P}=0.050$ for $\mathrm{OS})$ expression remained as the independent prognostic factors for DFS and OS. The present findings suggest that there may be an association between the combined downregulation of miR-335 and upregulation of Rock1 with tumor progression and adverse prognosis in patients with osteosarcoma.

\section{Introduction}

Osteosarcoma is the most common type of primary malignant tumor originating from bone in young adolescents (1). Although progress has been made in surgical technology and combined therapeutic strategies, the total survival rate of osteosarcoma remains poor, particularly in patients with lung metastasis (2). Several molecules, including cluster of differentiation 44, tumor protein p53, PLA2G16, vascular endothelial growth factor and periostin have been identified for their use in the prognosis of osteosarcoma (3-7). However, it was reported that p53 only predicted a decreased short-term survival rate, but not 3- or 5-year survival, and cluster of differentiation 44 expression level is not associated with overall survival rate and metastasis $(8,9)$. Therefore, it is important to identify novel and effective predictors of tumor progression and survival rate for patients with osteosarcoma. 
MicroRNAs (miRNAs) are transcribed from non-protein coding genes or introns, and mediate the translational suppression or cleavage of their target mRNAs by binding to the complementary sites of their 3'-untranslated region. The aberrant expression of miRNA, as oncogenes or anti-oncogenes, is observed in various types of cancer $(10,11)$. In osteosarcoma, certain miRNAs including miR-1247 and miR-27 have been identified as oncogenes $(12,13)$, while others, including miR-15a, miR-646 and miR-218, are regarded as anti-oncogenes (14-16). These previous findings prove that miRNAs are a key element in the tumorigenesis of osteosarcoma.

Previously, miR-335 has been identified as a tumor suppressor in multiple types of cancer, including pancreatic, ovarian, breast, small cell lung and renal cancer (17-21). Furthermore, our former study identified that miR-335 could inhibit the metastasis of osteosarcoma by directly targeting the regulation of Rho-associated serine-threonine protein kinase 1 (Rock1), in order to mediate Rho signaling (22). Until recently, there was little research focusing on the prognostic values of miR-335 and Rock1 in osteosarcoma. An increasing number of studies have revealed that combined miRNA and target gene expression profiling may provide vital information for the diagnosis and prognosis of numerous types of human cancer $(23,24)$. However, there have been a limited number of findings on the clinical significance of the combined expression of miR-335 and Rock1 in human osteosarcoma. Considering the aforementioned results, the present study hypothesized that there would be a connection between the combined abnormal expression of miR-335 and its target Rock1 with tumor progression and prognosis in patients with osteosarcoma.

The present study, examined miR-335 and Rock1 expression levels in osteosarcoma tissues and noncancerous bone tissues using in situ hybridization and immunohistochemistry, respectively. The clinical significance of abnormal miR-335 and Rock1 expression in osteosarcomas was explored.

\section{Materials and methods}

Patients and tissue samples. Approval for the present study was obtained from the Medical Ethics Committee of China Medical University (Liaoning, China). The need for written informed consents by the patients was waived due to the retrospective nature of the present study. A total of 91 osteosarcoma specimens were collected from patients with osteosarcoma who underwent curative tumor resection at the First Affiliated Hospital of China Medical University (Liaoning, China) between January 2003 and January 2008. During surgery, a total of 47 adjacent non-tumorous bone tissues were collected as controls. No patients underwent chemotherapy or radiotherapy prior to surgery. The clinical stage of the patients was classified according to the 6th edition of the Tumor Node Metastases Classification of Malignant Tumors, International Union against Cancer (25). The clinicopathological information for all patients is presented in Table I. All 91 patients with osteosarcoma were monitored during follow-up appointments, which lasted between 72 and 132 months. Mortality occurred in 9 patients during the follow-up period. The median overall survival (OS) and disease-free survival (DFS) of patients was 68 and 55 months, respectively.
In situ hybridization. miR-335 expression and subcellular localization in osteosarcoma tissues and matched noncancerous bone tissues were measured using in situ hybridization. Briefly, following the manufacturer's protocol, the tissue slides were mixed with 5'-digoxigenin LNA-modified-miR-335 (Exiqon A/S, Vedbaek, Denmark) using the IsHyb in situ Hybridization kit (BioChain Institute Inc., Eureka Drive, Newark, CA, USA).

Immunohistochemistry analysis. Rock1 protein expression and subcellular localization in osteosarcoma tissues and matched noncancerous bone tissues was detected using immunohistochemical staining. Firstly, tissue sections ( $4 \mu \mathrm{m}$ thick) were incubated with the rabbit monoclonal Rock1 antibody (dilution, 1:100; cat. no. ab134181; Abcam, Cambridge, UK) at $4^{\circ} \mathrm{C}$ overnight and subsequently incubated with biotinylated secondary antibodies (dilution, 1:1,000; cat. no. E043201; Dako; Agilent Technologies, Inc., Santa Clara, CA, USA) at $37^{\circ} \mathrm{C}$ for $30 \mathrm{~min}$. Samples were subsequently incubated with streptavidin horseradish peroxidase for another $30 \mathrm{~min}$ (LSAB kit; Dako; Agilent Technologies, Inc.) and stained with 3,3-diaminobenzidine. Finally, the slides were counterstained with hematoxylin, dehydrated in a graded ethanol series (absolute ethyl alcohol for $3 \mathrm{~min}, 95 \%$ ethanol for $3 \mathrm{~min}$ and $85 \%$ ethanol for $3 \mathrm{~min}$ ), then mounted. Negative control sections were performed under the same conditions, except without primary antibodies.

Evaluation of in situ hybridization and immunostaining. The immunoreactivity intensity was scored according to four values: 0) Negative staining; i) weak positive staining; ii) moderate positive staining; and iii) strong positive staining. The proportion of stained cells for that intensity over the total number of tumor cells on the slide was recorded in 5\% increments from a range of 0-100. The final immunoreactive score was obtained by multiplying the intensity score with the percentage of positively stained cells, and ranged between 0 and $300 \%$ and assigned with $5 \%$ increments $(0,5,10$, ...300\%). These scores were used to determine the cutoff value in receiver operating characteristic (ROC) curves to discriminate between tumors of high miR-335 or Rock1 expression and those of low expression. The sensitivity and specificity was plotted on ROC curves to investigate the survival status of patients with osteosarcoma.

Statistical analysis. All data were analyzed using SPSS 17.0 (SPSS, Inc., Chicago, IL, USA). The Student's $t$-test was used to compare the difference for data with normal distribution, while Wilcoxon rank-sum tests or Kruskal-Wallis tests were used to compare the difference for data with unequal variance. The association between miR-335 and Rock1 expression and clinicopathological characteristics in patients with osteosarcoma was evaluated using the Pearson's $\chi^{2}$ test or Fisher's exact probability test. The association between miR-335 and Rock1 expression was assessed by Spearman's rank correlation analysis. The Kaplan-Meier curves were plotted to demonstrate the survival difference, and the survival probabilities were assessed using a log-rank test. Univariate and multivariate Cox's proportional hazards regression models were used to assess the association of potential confounding variables with 
the OS or DFS. $\mathrm{P} \leq 0.05$ was considered to indicate a statistically significant difference.

\section{Results}

Subcellular localizations and expression patterns of miR-335 and Rockl in osteosarcoma tissues. In situ hybridization and immunohistochemistry analysis were used to confirm the subcellular localizations and the expression patterns of miR-335 and Rock1 protein in 91 osteosarcoma samples and 47 noncancerous bone samples respectively. As demonstrated in Fig. 1, miR-335 and Rock1 immunopositive staining were mainly localized in the cytoplasm. It was also observed that compared to noncancerous bone tissues, the miR-335 expression levels were considerably decreased in osteosarcoma tissues $(\mathrm{P}<0.001)$, while Rock1 expression levels increased significantly in osteosarcoma tissues $(\mathrm{P}<0.001)$.

Selection of the cutoff value for miR-335 and Rock1. ROC curve analysis was applied to determine an optimal cutoff value for the expression of miR-335 and ROCK1 in osteosarcoma samples. Considering the OS status, cutoff values of 115 and $87.5 \%$ were selected for the expression of miR-335 and Rock1, respectively (Fig. 2A and B). Tumors in which the immunohistological scores were $\geq 115$ and $<115 \%$ were defined as those of high and low expression of miR-335, respectively. Tumors with immunohistological scores $\geq 87.5$ and $<87.5 \%$ were defined as those with high and low expression of Rock1, respectively.

miR-335 expression associates with Rockl expression in osteosarcoma tissues. In Table II, it can be observed how miR-335 and Rock1 were expressed in 91 osteosarcoma samples. As shown in the cutoff value used in the present study, 11/91 (12.09\%) samples were of high miR-335 and high Rock1 expression, 11/91 (12.09\%) were of low miR-335 and low Rock1 expression, $31 / 91$ (34.07\%) were of high miR-335 expression, but low Rock1 expression, and 38/91 (41.76\%) were of low miR-335 expression but high Rock1 expression. There was a significant negative correlation between miR-335 and Rock1 expression in osteosarcoma tissues ( $r=-0.378, \mathrm{P}<0.001$, Table II), according to Spearman's correlation analysis.

Association between combined low-expression of miR-335 and high-expression of Rockl and the aggressive clinicopathological features of patients with osteosarcoma. As demonstrated in Table III, the low expression of miR-335 was significantly associated with distant metastasis $(\mathrm{P}=0.016)$ and grade IIB/III osteosarcoma $(\mathrm{P}=0.004)$. The high expression of Rock1 was also significantly associated with distant metastasis $(\mathrm{P}=0.022)$, grade IIB/III osteosarcoma $(\mathrm{P}=0.027)$ and higher tumor size $(\mathrm{P}=0.013)$. Table IV presents the association of combined miR-335 and Rock1 expression with distant metastasis and clinical stage. Out of all comparisons investigated in the present study, tumors with a high expression of Rock1 but low expression of miR-335 were the most strongly associated with distant metastasis $(\mathrm{P}=0.010)$ and a higher clinical stage $(\mathrm{P}=0.010)$.

Prediction of poor prognosis of osteosarcoma patients using combined downregulated miR-335 and upregulated Rock1. Kaplan-Meier analysis and log-rank test were used to evaluate
Table I. Clinicopathological characteristics of patients with osteosarcoma.

\begin{tabular}{|c|c|c|}
\hline Characteristics & No. of cases & $\%$ \\
\hline Age at diagnosis, years & 91 & \\
\hline$<18$ & 45 & 49.5 \\
\hline$\geq 18$ & 46 & 50.5 \\
\hline Gender & 91 & \\
\hline Female & 50 & 54.9 \\
\hline Male & 41 & 45.1 \\
\hline Tumor size, $\mathrm{cm}$ & 91 & \\
\hline$<5$ & 45 & 49.5 \\
\hline$\geq 5$ & 46 & 50.5 \\
\hline Anatomic location & 91 & \\
\hline Tibia/femur & 56 & 61.5 \\
\hline Elsewhere & 35 & 38.5 \\
\hline Histological subtype & 90 & \\
\hline Osteoblastic & 30 & 33.3 \\
\hline Chondroblastic & 30 & 33.3 \\
\hline Fibroblastic & 12 & 20.0 \\
\hline Mixed & 18 & 13.4 \\
\hline Clinical stage & 87 & \\
\hline I+IIA & 54 & 62.1 \\
\hline IIB/III & 33 & 37.9 \\
\hline Distant metastasis & 91 & 45.1 \\
\hline Absent & 55 & 60.4 \\
\hline Present & 36 & 39.6 \\
\hline
\end{tabular}

Table II. Expression of miR-335 and Rock1 proteins in 91 patients with osteosarcoma.

\begin{tabular}{lccc}
\hline & \multicolumn{2}{c}{ Rock1 expression } & \\
\cline { 2 - 3 } miR-335 & High $(\mathrm{n}=55)$ & Low $(\mathrm{n}=36)$ & P-value \\
\hline High $(\mathrm{n}=42)$ & 11 & 31 & $<0.001$ \\
Low $(\mathrm{n}=49)$ & 38 & 11 & \\
\hline
\end{tabular}

P-value obtained from Spearman's rank correlation test. miR, microRNA; Rock1, Rho-associated serine-threonine protein kinase 1.

the association of different miR-335 and Rock1 expression level with the OS or DFS in osteosarcoma patients. The data demonstrates that a high expression of Rock1 was significantly associated with shorter OS $(\mathrm{P}<0.001$, Fig. 3A) and DFS $(\mathrm{P}<0.001$, Fig. 3B), and the low expression of miR-335 was also evidently associated with shorter OS ( $\mathrm{P}<0.001$, Fig. 3C) and DFS $(\mathrm{P}<0.001$, Fig. 3D). Furthermore, univariate and multivariate Cox's proportional hazards regression models were used to evaluate the association of potential confounding variables with the OS or DFS.

Univariate results identified that gender ( $\mathrm{P}=0.020$ for $\mathrm{OS})$, higher tumor size $(\mathrm{P}=0.008$ for $\mathrm{DFS} ; \mathrm{P}=0.001$ for $\mathrm{OS})$, higher 
A

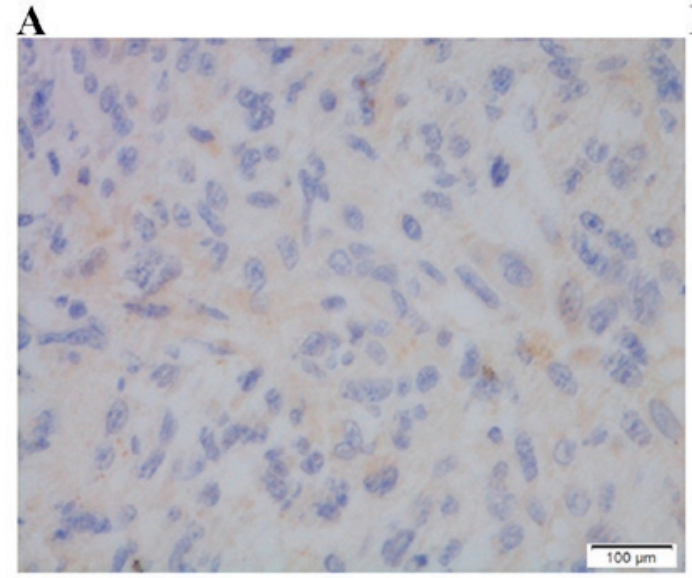

C

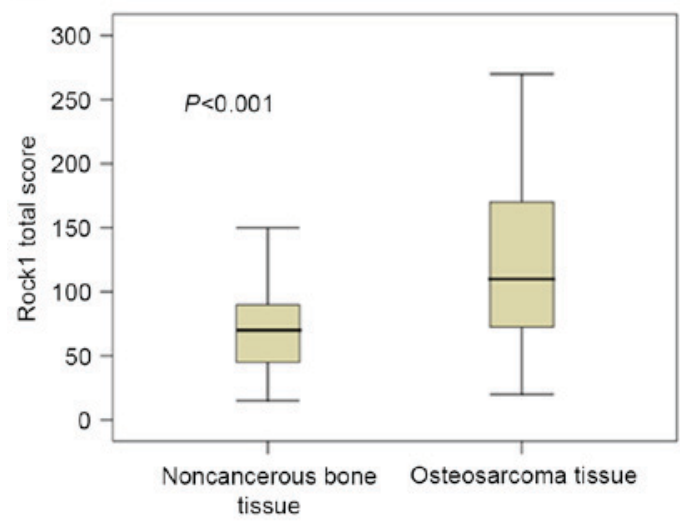

B

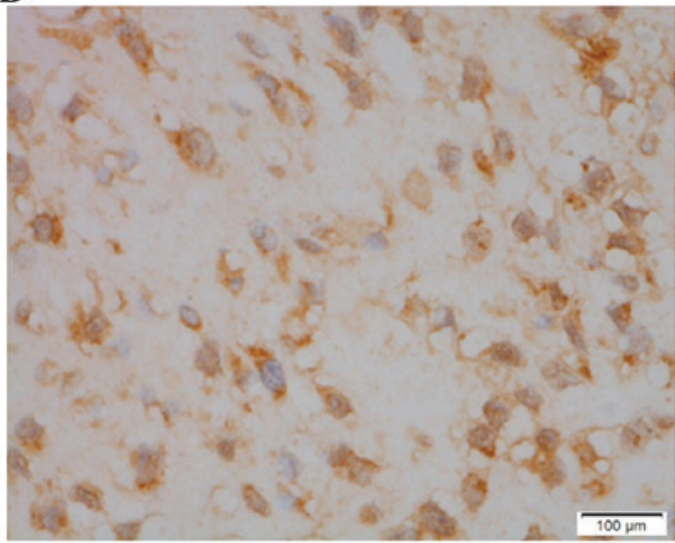

D

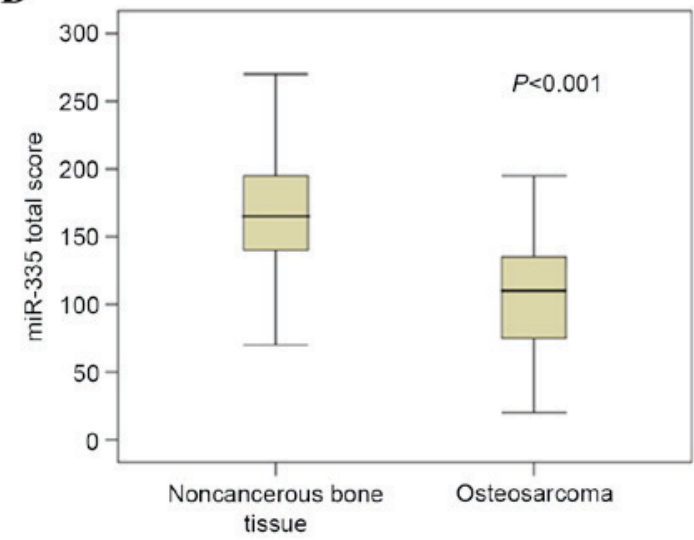

Figure 1. Comparison of protein expression in osteosarcoma and adjacent noncancerous bone tissues. Representative in situ hybridization images for miR-335 expression in (A) osteosarcoma tissues and (B) adjacent noncancerous bone tissues (original magnification, $\mathrm{x} 400$ ). Compared with the adjacent noncancerous bone tissues, the expression of (C) Rock1 protein was significantly increased, while (D) miR-335 was significantly decreased in osteosarcoma tissues. miR, microRNA; Rock1, Rho-associated serine-threonine protein kinase 1.
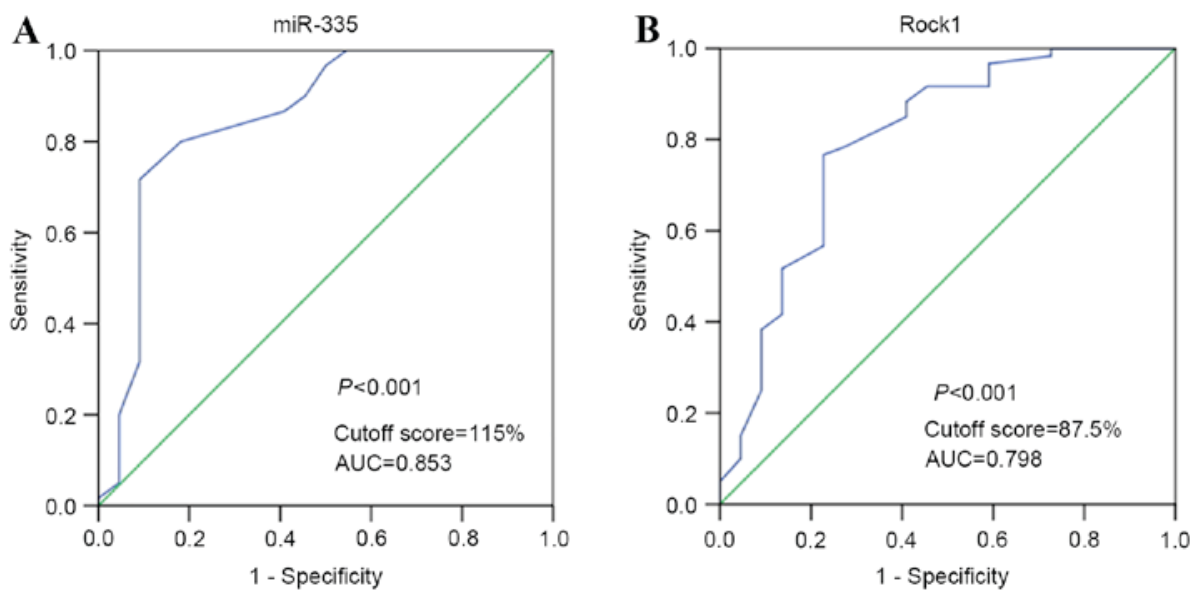

Figure 2. Receiver operating characteristic curves were used to determine the cutoff score for (A) miR-335 and (B) Rock1 expression based on the overall survival status of patients with osteosarcoma. The sensitivity and specificity for each outcome were plotted and the AUCs and P-value are indicated. miR, microRNA; Rock1, Rho-associated serine-threonine protein kinase 1; AUC, areas under curve.

clinical stage $(\mathrm{P}<0.001$ for $\mathrm{DFS} ; \mathrm{P}<0.001$ for $\mathrm{OS})$, distant metastasis $(\mathrm{P}=0.006$ for $\mathrm{DFS} ; \mathrm{P}<0.001$ for $\mathrm{OS}$ ), anatomic location $(\mathrm{P}<0.001$ for DFS), miR-335 low expression $(\mathrm{P}<0.001$ for DFS; $\mathrm{P}<0.001$ for OS) and high Rock1 expression ( $\mathrm{P}<0.001$ for DFS; $\mathrm{P}=0.001$ for OS), were associated with the OS and DFS in patients with osteosarcoma (Table V). In addition, multivariate Cox regression analysis identified that higher clinical stage ( $\mathrm{P}=0.002$ for $\mathrm{DFS} ; \mathrm{P}=0.015$ for $\mathrm{OS}$ ), distant metastasis $(\mathrm{P}=0.024$ for DFS; $\mathrm{P}=0.002$ for OS) and low expression of miR-335 $(\mathrm{P}<0.001$ for DFS; $\mathrm{P}=0.002$ for OS) remained independent 
Table III. Association of miR-335 and Rock1 expression with the clinicopathological features of patients with osteosarcoma.

\begin{tabular}{|c|c|c|c|c|c|}
\hline Characteristics & No. of cases & miR-335 low, n (\%) & P-value & Rock1 high, n (\%) & P-value \\
\hline Age at diagnosis, years & & & 0.746 & & 0.346 \\
\hline$<18$ & 45 & $25(55.6)$ & & $25(55.6)$ & \\
\hline$\geq 18$ & 46 & $24(52.2)$ & & $30(65.2)$ & \\
\hline Gender & & & 0.845 & & 0.722 \\
\hline Female & 40 & $22(55.0)$ & & $25(62.5)$ & \\
\hline Male & 51 & $27(52.9)$ & & $30(58.8)$ & \\
\hline Tumor size, $\mathrm{cm}$ & & & 0.113 & & 0.013 \\
\hline$<5$ & 46 & $21(45.7)$ & & $22(47.8)$ & \\
\hline$\geq 5$ & 45 & $28(62.2)$ & & $33(73.3)$ & \\
\hline Anatomic location & & & 0.618 & & 0.090 \\
\hline Tibia/femur & 56 & $29(51.8)$ & & $30(53.6)$ & \\
\hline Elsewhere & 35 & $20(57.1)$ & & $25(71.4)$ & \\
\hline Histological subtype & & & 0.067 & & 0.510 \\
\hline Osteoblastic & 30 & $11(36.7)$ & & $16(53.3)$ & \\
\hline Chondroblastic & 30 & $19(63.3)$ & & $19(63.3)$ & \\
\hline Fibroblastic & 12 & $6(50.0)$ & & $6(50.0)$ & \\
\hline Mixed & 18 & $13(72.2)$ & & $5(27.8)$ & \\
\hline Clinical stage & & & 0.004 & & 0.027 \\
\hline I+IIA & 54 & $22(40.7)$ & & $28(51.9)$ & \\
\hline IIB/III & 33 & $24(72.7)$ & & $25(75.8)$ & \\
\hline Distant metastasis & & & 0.016 & & 0.022 \\
\hline Absent & 55 & $24(43.6)$ & & $28(50.9)$ & \\
\hline Present & 36 & $25(69.4)$ & & $27(75.0)$ & \\
\hline
\end{tabular}

P-value obtained from Pearson's $\chi^{2}$ or Fisher's exact test. miR, microRNA; Rock1, Rho-associated serine-threonine protein kinase 1.

Table IV. Association of the combination of miR-335 and Rock1 expression with clinical stage and distant metastasis of osteosarcoma.

\begin{tabular}{|c|c|c|c|c|c|}
\hline \multirow[b]{2}{*}{ Variables } & \multirow[b]{2}{*}{ No. of cases } & \multicolumn{3}{|c|}{ miR-335 and Rock1 expression } & \multirow[b]{2}{*}{ P-value } \\
\hline & & $\begin{array}{c}\text { miR-335-low/ } \\
\text { Rock1-high, n (\%) }\end{array}$ & Both high or low & $\begin{array}{c}\text { miR-335-high/ } \\
\text { Rock1-low, n (\%) }\end{array}$ & \\
\hline Clinical stage & & & & & 0.010 \\
\hline $\mathrm{I}+\mathrm{IIA}$ & 54 & $17(31.5)$ & $16(29.6)$ & $21(38.9)$ & \\
\hline IIB/III & 33 & $20(60.6)$ & $9(27.3)$ & $4(12.1)$ & \\
\hline Distant metastasis & & & & & 0.010 \\
\hline Absent & 55 & $16(29.1)$ & $20(36.4)$ & $19(34.5)$ & \\
\hline Present & 33 & $22(61.1)$ & $8(22.2)$ & $6(16.7)$ & \\
\hline
\end{tabular}

P-value obtained from Pearson's $\chi^{2}$ test or Fisher's exact text. miR, microRNA; Rock1, Rho-associated serine-threonine protein kinase.

prognostic factors for OS in patients with osteosarcoma. Subsequently, the present study combined miR-335 and Rock1 expression into three groups: High expression of miR-335 and Rock1, either high expression of miR-335 or Rock1, and low expression miR-335 and Rock1 to investigate whether the combined expression of miR-335 and Rock1 exhibited an effect on the progression and prognosis of osteosarcoma.
Kaplan-Meier analysis and log-rank tests (Fig. 3E and F) revealed that the OS and DFS of patients with high expression of Rock 1 and low expression of miR-335 was considerably shorter compared with those with high or low expression of miR-335 and Rock1, and those with low Rock1 expression and high miR-335 expression $(\mathrm{P}<0.001$ for the two). Results of univariate and multivariate Cox proportional hazards 
Table V. Univariate Cox regression analysis of OS and DFS in patients with osteosarcoma.

\begin{tabular}{|c|c|c|c|c|}
\hline \multirow[b]{2}{*}{ Category } & \multicolumn{2}{|c|}{ Disease-free survival } & \multicolumn{2}{|c|}{ Overall survival } \\
\hline & $\mathrm{RR}(95 \% \mathrm{CI})$ & P-value & $\mathrm{RR}(95 \% \mathrm{CI})$ & P-value \\
\hline Age, years $(\geq 18 /<18)$ & $1.151(0.714-1.855)$ & 0.564 & $1.172(0.705-1.946)$ & 0.541 \\
\hline Gender (male/female) & $1.105(0.681-1.793)$ & 0.686 & $0.951(0.570-1.588)$ & 0.020 \\
\hline Tumor size, cm $(\geq 5.0 /<5.0)$ & $1.912(1.184-3.090)$ & 0.008 & $2.326(1.388-3.897)$ & 0.001 \\
\hline Clinical stage (IB/III/I+IIA) & $4.031(2.377-6.834)$ & $<0.001$ & $4.098(2.396-7.011)$ & $<0.001$ \\
\hline $\begin{array}{l}\text { Histological subtype (mixed/fibroblastic/ } \\
\text { (Mixed/fibroblastic/chondroblastic/osteoblastic) }\end{array}$ & $1.052(0.870-1.272)$ & 0.603 & $1.051(0.858-1.288)$ & 0.630 \\
\hline Distant metastasis (present/absent) & $1.991(1.216-3.259)$ & 0.006 & $3.450(1.999-5.954)$ & $<0.001$ \\
\hline Anatomic location (elsewhere/tibia/femur) & $2.513(1.63-3.87)$ & $<0.001$ & $1.539(0.919-2.578)$ & 0.101 \\
\hline miR-335 expression (negative/positive) & $0.310(0.184-0.523)$ & $<0.001$ & $0.287(0.163-0.507)$ & $<0.001$ \\
\hline Rock1 expression (positive/negative) & $2.633(1.528-4.535)$ & $<0.001$ & $2.887(1.579-5.276)$ & 0.001 \\
\hline $\begin{array}{l}\text { miR-335/Rock1 expression } \\
\text { (miR-335-low and Rock1-high/others) }\end{array}$ & $2.542(1.553-4.161)$ & $<0.001$ & $2.931(1.735-4.950)$ & $<0.001$ \\
\hline
\end{tabular}

OS, overall survival; DFS, disease free survival; RR, relative risk; CI, confidence interval; miR, microRNA; Rock1, Rho-associated serine-threonine protein kinase.

Table VI. Multivariate cox regression analysis of OS and DFS in osteosarcoma patients.

\begin{tabular}{|c|c|c|c|c|}
\hline \multirow[b]{2}{*}{ Category } & \multicolumn{2}{|c|}{ Disease-free survival } & \multicolumn{2}{|c|}{ Overall survival } \\
\hline & $\mathrm{RR}(95 \% \mathrm{CI})$ & P-value & $\mathrm{RR}(95 \% \mathrm{CI})$ & P-value \\
\hline Gender (male/female) & - & - & $0.748(0.428-1.306)$ & 0.307 \\
\hline Tumor size, $\mathrm{cm}(\geq 5.0 /<5.0)$ & $1.324(0.776-2.287)$ & 0.314 & $1.810(0.964-3.398)$ & 0.065 \\
\hline Clinical stage (IB/III/I+IIA) & $2.607(1.427-4.762)$ & 0.002 & $2.243(1.169-4.305)$ & 0.015 \\
\hline Distant metastasis (present/absent) & $1.956(1.091-3.506)$ & 0.024 & $3.056(1.514-6.167)$ & 0.002 \\
\hline Anatomic location (elsewhere/tibia/femur) & $1.443(0.855-2.434)$ & 0.169 & $1.119(0.637-1.965)$ & 0.696 \\
\hline miR-335 expression (negative/positive) & $0.173(0.065-0.459)$ & $<0.001$ & $0.170(0.056-0.519)$ & 0.002 \\
\hline Rock1 expression (positive/negative) & $2.182(0.917-5.190)$ & 0.078 & $2.469(0.903-6.755)$ & 0.078 \\
\hline $\begin{array}{l}\text { miR-335/Rock1 expression } \\
\text { (miR-335-low and Rock1-high/others) }\end{array}$ & $0.243(0.073-0.807)$ & 0.021 & $0.253(0.064-0.998)$ & 0.050 \\
\hline
\end{tabular}

OS, overall survival; DFS, disease free survival; RR, relative risk; CI, confidence interval; miR, microRNA; Rock1, Rho-associated serinethreonine protein kinase 1 .

regression analysis are presented in Table VI. The findings demonstrate that combined high Rock1 expression and low miR-335 expression was considered as an independent prognostic factor for shorter OS $(\mathrm{P}=0.050)$ and DFS $(\mathrm{P}=0.021)$ in patients with osteosarcoma.

\section{Discussion}

The present study used a number of clinical samples in order to attempt to detect the combined expression of miR-335 and its target gene Rock1 in osteosarcoma tissues, to analyze its association with osteosarcoma clinicopathological characteristic and to assess the correlation of combined miR-335 and Rock1 expression with the prognosis of patients with osteosarcoma. The present findings provide evidence that the combined downregulation of miR-335 and upregulation of Rock1 may be associated with the progression and undesirable prognosis in osteosarcoma.

Recently, numerous studies have reported that miRNAs, which target various oncogenes or anti-oncogenes, may perform a diverse role in tumorigenesis (26-28). Therefore, miRNAs are suggested as a type of prognostic biomarker and potential therapeutic site for tumor treatment. As a transcript of genomic region chromosome 7q32.2, the function of miR-335 has been widely reported (29). It was revealed that miR-335 functions as a tumor suppressor in malignant tumors and that the loss of miR-335 expression may lead to the progression of aggressive tumor phenotypes. Wang et al (30) reported that miR-335 could directly suppress B-cell lymphoma 2 and lead to inhibition of the proliferation and invasion in renal 

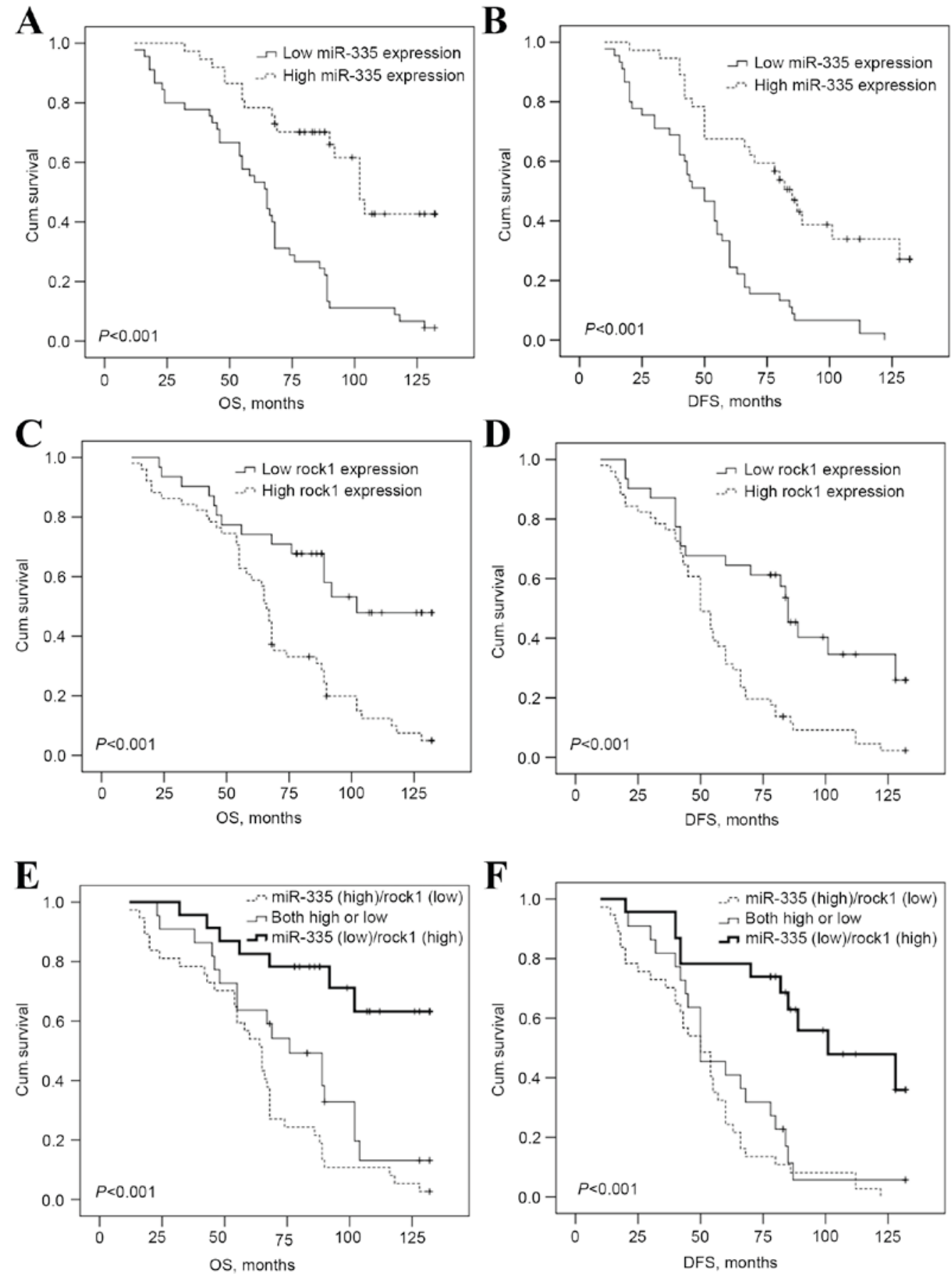

Figure 3. Kaplan-Meier survival analysis of miR-335 and Rock1 expression in patients with osteosarcoma. Survival curves show the association between miR-335 expression and (A) OS or (B) DFS in patients with osteosarcoma. Survival curves show the association between Rock1 expression and (C) OS and (D) DFS in 91 patients with osteosarcoma. Survival curves show the association between the combined expression of miR-335 and Rock1 and (E) OS or (F) DFS in patients with osteosarcoma. miR, microRNA; Rock1, Rho-associated serine-threonine protein kinase 1; OS, overall survival; DFS, disease free survival.

cell carcinoma cells. Gao et al (18) reported that miR-335 could target the regulatory oncoprotein c-Met and suppress the migration of breast cancer cells. However, miR-335 also functions as a tumor oncogene in certain types of cancer. Shu et al (31) identified that targeting oncogenic miR-335 suppressed the growth and invasion of malignant astrocytoma cells. Shi et al (32) reported that miR-335 directly targeted retinoblastoma 1 and promoted meningiomas cellular proliferation. In a previous study, we revealed that miR-335 could target Rock1 and cause the suppression of migration and invasion in osteosarcoma cells (22). Our data proved that there is a marked decline in the expression levels of miR-335 in human osteosarcoma tissues compared with noncancerous bone tissues, and that there is also a close correlation of downregulated miR-335 expression with osteosarcoma progression, and even adverse outcomes in patients with osteosarcoma, which increases evidence that miR-335 may be a tumor suppressor in osteosarcoma.

Rock consists of two isoforms, Rock1 and Rock2 (23), and is the key kinase of Rho signaling (22). Activated Rocks promote the reassembly of focal contacts and the formation of stress-fibers while interacting with the actin 
cytoskeleton (33). Subsequently, this regulates various cellular processes, including cellular proliferation, assembly of focal adhesion, fomation of invadopodium and actomyosin contractility (34). An increasing number of evidence demonstrates the key role Rocks perform in oncogenesis, particularly regarding Rock1. Oellers et al (35) identified that Rock1 was essential for glioma cell migration on myelinated axons. Kamai et al (36) revealed a prominent association of the Rho/Rock pathway with the invasion/migration of bladder cancer. Akagi et al (37) demonstrated that Rock1 could be a novel prognostic marker in vulvar cancer. In osteosarcoma, Liu et al (38) revealed that the downregulation of Rock1 could suppress proliferation but promote apoptosis in osteosarcoma cells. Cai et al (23) identified that the high expression of Rock1 was significantly associated with the metastasis of osteosarcoma and the response to preoperative chemotherapy. The present study identified a significant elevation of Rock1 but decreased expression of miR-335 in human osteosarcoma tissues. Evidence also demonstrated that there was a close correlation of the upregulated Rock1 expression with osteosarcoma progression and adverse outcomes in patients with osteosarcoma, which additionally suggests that Rock1 may be an oncogene in osteosarcoma.

However, whether the combined expression of miR-335 and Rock1 is applicable for use in the clinical setting remains unknown in osteosarcoma. The findings of the present study demonstrate that the combined high expression of Rock1 and low expression of miR-335 was positively associated with distant metastasis, higher clinical stage and worse OS and DFS. Therefore, the prediction of advanced tumor progression and unfavorable prognosis can be determined by the downregulation of miR-335 and the upregulation of its target gene, Rock1, for patients with osteosarcoma.

In summary, miR-335 was identified to be downregulated, while Rock1 was upregulated in patients with osteosarcoma. Additionally, the combined high expression of Rock1 and low expression of miR-335 was positively correlated with distant metastasis, higher clinical stage, and poor OS and DFS. In addition, multivariate survival analysis demonstrated that the combined low expression of miR-335 and high expression of Rock1 were independent prognostic factors for OS and DFS. Finally, data in the present study provided evidence that the combined downregulation of miR-335 and upregulation of Rock1 may be associated with tumor progression and poor prognosis in patients with osteosarcoma.

\section{Acknowledgements}

The present study was supported by grants from the National Natural Science Foundation of China (grant no. 81502333), the China Postdoctoral Science Foundation (grant no., 2016M591437), the PhD Start-up Research Foundation of Liaoning Province (grant no. 201601225), the Education Fund Item of Liaoning Province (grant no., L2014418) and the SMC General Science Foundation (grant no. 20151002).

\section{References}

1. Gill J, Ahluwalia MK, Geller D and Gorlick R: New targets and approaches in osteosarcoma. Pharmacol Ther 137: 89-99, 2013.
2. Ta HT, Dass CR, Choong PF and Dunstan DE: Osteosarcoma treatment: State of the art. Cancer Metastasis Rev 28: 247-263, 2009.

3. Chen D, Zhang YJ, Zhu KW and Wang WC: A systematic review of vascular endothelial growth factor expression as a biomarker of prognosis in patients with osteosarcoma. Tumour Biol 34: 1895-1899, 2013.

4. Fu HL, Shao L, Wang Q, Jia T, Li M and Yang DP: A systematic review of p53 as a biomarker of survival in patients with osteosarcoma. Tumour Biol 34: 3817-3821, 2013.

5. Hu F, Shang XF, Wang W, Jiang W, Fang C, Tan D and Zhou HC: High-level expression of periostin is significantly correlated with tumour angiogenesis and poor prognosis in osteosarcoma. Int J Exp Pathol 97: 86-92, 2016

6. Liang S, Ren Z, Han X, Yang J, Shan L, Li L, Wang B, Zhang Q, $\mathrm{Mu} \mathrm{T}$, Chen K, et al: PLA2G16 expression in human osteosarcoma is associated with pulmonary metastasis and poor prognosis. PloS One 10: e0127236, 2015.

7. Liu Y, Wu Y, Gu S, Sun Z, Rui Y, Wang J, Lu Y, Li H, Xu K and Sheng P: Prognostic role of CD44 expression in osteosarcoma: Evidence from six studies. Diagn Pathol 9: 140, 2014.

8. Yao D, Cai GH, Chen J, Ling R, Wu SX and Li YP: Prognostic value of p53 alterations in human osteosarcoma: A meta analysis. Int J Clin Exp Pathol 7: 6725-6733, 2014.

9. Liu Y, Wu Y, Gu S, Sun Z, Rui Y, Wang J, Lu Y, Li H, Xu K and Sheng P: Prognostic role of CD44 expression in osteosarcoma: Evidence from six studies. Diagn Pathol 9: 140, 2014.

10. Calin GA and Croce CM: MicroRNA signatures in human cancers. Nat Rev Cancer 6: 857-866, 2006.

11. Kumar MS, Lu J, Mercer KL, Golub TR and Jacks T: Impaired microRNA processing enhances cellular transformation and tumorigenesis. Nat Genet 39: 673-677, 2007.

12. Pan W, Wang H, Jianwei R and Ye Z: MicroRNA-27a promotes proliferation, migration and invasion by targeting MAP2K4 in human osteosarcoma cells. Cell Physiol Biochem 33: 402-412, 2014.

13. Zhao F, Lv J, Gan H, Li Y, Wang R, Zhang H, Wu Q and Chen Y: MiRNA profile of osteosarcoma with CD117 and stro-1 expression: miR-1247 functions as an onco-miRNA by targeting MAP3K9. Int J Clin Exp Pathol 8: 1451-1458, 2015.

14. Jin J, Cai L, Liu ZM and Zhou XS: miRNA-218 inhibits osteosarcoma cell migration and invasion by down-regulating of TIAM1, MMP2 and MMP9. Asian Pac J Cancer Prev 14: 3681-3684, 2013.

15. Sun XH, Geng XL, Zhang J and Zhang C: miRNA-646 suppresses osteosarcoma cell metastasis by downregulating fibroblast growth factor 2 (FGF2). Tumour Biol 36: 2127-2134, 2015.

16. Tian X, Zhang J, Yan L, Dong JM and Guo Q: MiRNA-15a inhibits proliferation, migration and invasion by targeting TNFAIP1 in human osteosarcoma cells. Int J Clin Exp Pathol 8: 6442-6449, 2015.

17. Cao J, Cai J, Huang D, Han Q, Yang Q, Li T, Ding H and Wang Z: miR-335 represents an invasion suppressor gene in ovarian cancer by targeting Bcl-w. Oncol Rep 30: 701-706, 2013.

18. Gao L, Yang Y, Xu H, Liu R, Li D, Hong H, Qin M and Wang Y: MiR-335 functions as a tumor suppressor in pancreatic cancer by targeting OCT4. Tumour Biol 35: 8309-8318, 2014.

19. Gao Y, Zeng F, Wu JY, Li HY, Fan JJ, Mai L, Zhang J, Ma DM, Li Y and Song FZ: MiR-335 inhibits migration of breast cancer cells through targeting oncoprotein c-Met. Tumour Biol 36: 2875-2883, 2015.

20. Gong M, Ma J, Guillemette R, Zhou M, Yang Y, Yang Y, Hock JM and Yu X: miR-335 inhibits small cell lung cancer bone metastases via IGF-IR and RANKL pathways. Mol Cancer Res 12: 101-110, 2014

21. Wang K, Chen X, Zhan Y, Jiang W, Liu X, Wang X and Wu B: miR-335 inhibits the proliferation and invasion of clear cell renal cell carcinoma cells through direct suppression of BCL-W. Tumour Biol 36: 6875-6882, 2015.

22. Wang Y, Zhao W and Fu Q: miR-335 suppresses migration and invasion by targeting ROCK1 in osteosarcoma cells. Mol Cell Biochem 384: 105-111, 2013.

23. Cai H, Lin L, Tang M and Wang Z: Combined microRNA-340 and ROCK1 mRNA profiling predicts tumor progression and prognosis in pediatric osteosarcoma. Int J Mol Sci 15: 560-573, 2014.

24. Yu L, Zhang J, Guo X, Li Z and Zhang P: MicroRNA-224 upregulation and AKT activation synergistically predict poor prognosis in patients with hepatocellular carcinoma. Cancer Epidemiol 38: 408-413, 2014. 
25. Spiessl B, Scheibe O and Wagner G, (eds): Soft tissue sarcomas. In: International Union Against Cancer (UICC) TNM-Atlas. Illustrated Guide to the Classification of Malignant Tumours. Springer-Verlag, Berlin, pp170-172.

26. Liu P, Zhang H, Liang X, Ma H, Luan F, Wang B, Bai F, Gao L and $\mathrm{Ma} \mathrm{C}$ : $\mathrm{HBV}$ preS2 promotes the expression of TAZ via miRNA-338-3p to enhance the tumorigenesis of hepatocellular carcinoma. Oncotarget 6: 29048-29059, 2015.

27. Santhi WS, Prathibha R, Charles S, Anurup KG, Reshmi G, Ramachandran S, Jissa VT, Sebastian P and Radhakrishna Pillai M: Oncogenic microRNAs as biomarkers of oral tumorigenesis and minimal residual disease. Oral Oncol 49: 567-575, 2013.

28. Xu C, Zeng Q, Xu W, Jiao L, Chen Y, Zhang Z, Wu C, Jin T, Pan A, Wei R, et al: miRNA-100 inhibits human bladder urothelial carcinogenesis by directly targeting mTOR. Mol Cancer Ther 12: 207-219, 2013.

29. Shu M, Zhou Y, Zhu W, Zhang H, Wu S, Chen J and Yan G: MicroRNA 335 is required for differentiation of malignant glioma cells induced by activation of cAMP/protein kinase A pathway. Mol Pharmacol 81: 292-298, 2012.

30. Wang K, Chen X, Zhan Y, Jiang W, Liu X, Wang X and Wu B miR-335 inhibits the proliferation and invasion of clear cell renal cell carcinoma cells through direct suppression of BCL-W. Tumour Biol 36: 6875-6882, 2015.
31. Shu M, Zheng X, Wu S, Lu H, Leng T, Zhu W, Zhou Y, Ou Y, Lin X, Lin Y, et al: Targeting oncogenic miR-335 inhibits growth and invasion of malignant astrocytoma cells. Mol Cancer 10: 59, 2011.

32. Shi L, Jiang D, Sun G, Wan Y, Zhang S, Zeng Y, Pan T and Wang Z: miR-335 promotes cell proliferation by directly targeting Rb1 in meningiomas. J Neurooncol 110: 155-162, 2012.

33. Schofield AV and Bernard O: Rho-associated coiled-coil kinase (ROCK) signaling and disease. Crit Rev Biochem Mol Biol 48: 301-316, 2013.

34. Patel RA, Liu Y, Wang B, Li R and Sebti SM: Identification of novel ROCK inhibitors with anti-migratory and anti-invasive activities. Oncogene 33: 550-555, 2014.

35. Oellers P, Schröer U, Senner V, Paulus W and Thanos S: ROCKs are expressed in brain tumors and are required for glioma-cell migration on myelinated axons. Glia 57: 499-509, 2009.

36. Kamai T, Tsujii T, Arai K, Takagi K, Asami H, Ito Y and Oshima H: Significant association of Rho/ROCK pathway with invasion and metastasis of bladder cancer. Clin Cancer Res 9: 2632-2641, 2003.

37. Akagi EM, Lavorato-Rocha AM, Maia Bde M, Rodrigues IS, Carvalho KC, Stiepcich MM, Baiocchi G, Sato-Kuwabara Y, Rogatto SR, Soares FA and Rocha RM: ROCK1 as a novel prognostic marker in vulvar cancer. BMC cancer 14: 822, 2014.

38. Liu X, Choy E, Hornicek FJ, Yang S, Yang C, Harmon D, Mankin $\mathrm{H}$ and Duan Z: ROCK1 as a potential therapeutic target in osteosarcoma. J Orthop Res 29: 1259-1266, 2011. 